\title{
Trasplante de órganos, una mirada desde el judaísmo en el siglo XXI
}

Centro de Bioética,

Facultad de Medicina Clínica AlemanaUniversidad del Desarrollo. Santiago de Chile.

aAlumna de Medicina y Ayudante Alumna.

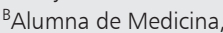
Facultad de Medicina Clínica AlemanaUniversidad del Desarrollo.

Recibido el 16 de abril de 2012, aceptado el 6 de julio de 2012

Correspondencia a: Dra. Lorna Luco Av. Las Condes 12438, Lo Barnechea. Tel: 5760711 E-mail: lornamuriel@gmail. com

\author{
NICOLE GROSSMAN K. ${ }^{1, a}$, JAVIERA HERRERA V. ${ }^{1, b}$, LORNA LUCO C. ${ }^{1}$
}

\section{The point of view of Judaism on organ donation}

Organ transplantation frequently constitutes a source of public concern. Dealing with such a complex medical problems requires a process of recognition of the different attitudes that social groups have toward organ transplantation attitudes which might vary accordingly to cultural and religious diversity. Judaism is the focus of this review. Our objective is to contribute to the knowledge that Chilean health professionals have about the Jewish point of view on organ transplantation. The supreme value of life is a premise of Judaism, so saving a life should precede the enforcement of certain Old Testament's prohibitions. However, it is difficult and misleading to attempt to define a unique point of view-even though there is an overwhelming majority who are in favor of organ donation-because different theological interpretations and recommendations are continuously in debate. We conclude that the mainstream Jewish position is not significantly different from the contemporary Western thought, even though a minority in Judaism is opposed to cadaveric organ donation.

(Rev Med Chile 2012; 140: 1352-1354").

Key words: Brain death; Judaism, brain; Organ Transplantation.
Quién salva una vida, salva al mundo entero.

Tratado Sanhedrín 37a, Talmud.

41 1 trasplante de órganos es un tema siempre vigente que no deja indiferente a nadie. El promedio mundial de donantes de órganos fue de 15 donantes por millón de habitantes. En España, esta tasa es de 32 donantes por millón ${ }^{1}$. En Chile, la tasa de donación de órganos en el año 2009 fue de 6,5 donantes por millón de habitantes, y en el 2010 disminuyó a 5,42 . Esto podría reflejar que existe poca conciencia, escaso interés, o simplemente desinformación del tema en nuestra sociedad. Esta cifra es la menor registrada desde el año 1998. La información entregada por el Instituto de Salud Pública a la Corporación del Trasplante en Chile, indica que existen actualmente 1.818 personas en espera de un órgano, $15 \%$ son menores de 15 años. Alrededor de 40 de ellos, se transformarán en pacientes de prioridad nacional cada año ${ }^{3}$.

La actitud social frente al tema, tanto de la población en general como de profesionales de la salud, varía de acuerdo a las diferentes culturas y creencias. Es por ello que se necesita comprender los distintos conceptos sobre salud-enfermedad de las personas originarias de distintas culturas que conviven en nuestro país, para saber cómo abordar los problemas más complejos en relación a tratamientos médicos.

El judaísmo es una religión con más de 3.000 años de antigüedad que se basa en la Torá Escrita (Antiguo Testamento) y en la Torá Oral, conocida como Talmud (transcripción de la tradición oral), que fue entregada a Moisés en el Sinaí, y que a su vez, explica la Torá Escrita.

A través de una revisión analizaremos la postura de la religión judía, en relación a los trasplantes de órganos, de la que se conoce muy poco en Chile, con el fin de contribuir a su mejor comprensión por parte de los profesionales de la salud y de la sociedad en general.

\section{Desmitificación de la no donación}

Aunque existe una percepción generalizada de que el judaísmo es contrario a la donación de órganos, ésta no es la realidad. En 1990 la Asamblea Rabínica Ortodoxa de Estados Unidos de 
Norteamérica adoptó una resolución en la cual motiva a todos los judíos a que sean donantes de tejidos y órganos, firmando y llevando consigo tarjetas de identificación en las que se afirme su decisión de ser donantes en caso de fallecer ${ }^{4}$. En el judaísmo, los trasplantes de corazón, pulmón, riñón, hígado y otros órganos vitales no solamente están permitidos, sino que son considerados como parte de un mandato basado en el valor supremo de la vida humana ${ }^{5}$. Esto ilustra la importancia que le da el judaísmo a la vida por sobre todas las cosas.

Sin embargo, dado que no existe una posición única y jerárquica como en otras religiones, algunas corrientes del judaísmo son aún reacias a la donación de órganos, en base al argumento de la resurrección de los cuerpos. El pueblo judío está esperando la llegada del Mesías, momento en el cual todas las almas resucitarán y serán parte de esa época mesiánica. Es por ello, que estos sectores minoritarios consideran que cuando llegue ese momento sus cuerpos no estarían completos. Sin embargo, el Rabino Dr. Mordechai Halperin, Director del Falk Schlesinger Institute for MedicalHalachical Research, responde que el donante no cambia su status para el momento de la resurrección cuando llegue el Mesías y aún más, que el donar un órgano para salvar una vida llega incluso a ser considerado un precepto. Así, aunque existan distintas líneas de pensamiento en el judaísmo, todas comparten el enunciado: "Quién salva una vida, salva al mundo entero".

Según esta posición, la donación de órganos sería una "Mitzvá" (un mandamiento o precepto). De acuerdo a este precepto habría tres prohibiciones bíblicas referentes al cadáver, las cuales podrían llevar a pensar que la donación de órganos debiese estar prohibida: "Nivul Hamet", que es la prohibición de la mutilación innecesaria de un cadáver; "Halanat Hamet", que prohíbe retrasar el entierro de un cuerpo; y "Hanaát Hamet", que prohíbe obtener algún beneficio de un cadáver'.

Estas prohibiciones cuidan el respeto y dignidad de los cadáveres, porque ellos alguna vez fueron portadores de una vida y de su alma. Sin embargo, la mayoría de los Rabinos están de acuerdo en que es más importante aplicar "Pikuach Nefesh" (Salvación del Alma), que respetar estas prohibiciones, ya que el trasplante de órganos salva vidas y, por ende, se está cumpliendo una "Mitzvá" mayory se está dando un mayor respeto y dignidad al cuerpo humano.

\section{Donación de órganos en pacientes vivos}

En Chile, la Ley N ${ }^{\circ} 20.413$ de Donaciones en su artículo cuarto ${ }^{7}$, señala que la donación de órganos por donante vivo sólo se permitirá en personas capaces mayores de dieciocho años y debe ser idealmente un donante relacionado, con el fin de evitar el comercio de órganos.

El judaísmo, en relación al trasplante de órganos con donante vivo, señala que es tan importante evaluar los riesgos del donante como el estado del receptor. Por ejemplo, el trasplante de médula ósea conlleva sólo un riesgo mínimo para el donante y por ende está permitido ${ }^{8}$. Es también importante considerar si el paciente aún está a tiempo de recibir el órgano y por lo tanto, utilizar este criterio al momento de realizar el trasplante.

La escasez de órganos ha planteado en diversos países un debate acerca de la donación altruista de órganos a pacientes no relacionados, con la ventaja de aumentar la donación de órganos para trasplante, aunque existe la duda de que surjan formas de compensación o venta de órganos. Existe un programa llamado "Kidney Mitzvah" en Estados Unidos de Norteamérica e Israel que busca judíos que quieran donar uno de sus riñones a pacientes judíos no relacionados que lo necesiten. Este programa trabaja a su vez con la organización estadounidense "National Kidney Registry".

\section{Donación de órganos y muerte encefálica}

Por consenso general y apoyado por la legislación vigente en Chile, los órganos para la donación son extraídos una vez certificada la muerte encefálica, mediante las pruebas diagnósticas correspondientes.

Esta condición se define como la abolición total e irreversible de la función de todo el encéfalo, incluido el tronco encefálico9 ${ }^{9}$ La declaración de muerte encefálica debe ser segura e inequívoca y para esto existen protocolos, a nivel nacional, que se aplican con la mayor rigurosidad frente al donante presunto.

Para el judaísmo, la discusión primordial es la declaración de la muerte y los criterios que determinan que una persona ha fallecido. Hay un debate rabínico en el Talmud referente a la definición de muerte. La pregunta central en esta discusión es en qué momento una persona es declarada muerta. Una opinión tradicional señala la muerte como el 
cese de la respiración y la otra lo hace respecto al cese irreversible del latido cardiaco.

La pregunta central es si la ley judía considera viva o muerta a una persona con muerte encefálica cuyo corazón sigue latiendo y que está conectada a ventilación mecánica. Si la "Halajá" (ley judía) considera a esta persona como viva, la extracción de sus órganos estaría necesariamente prohibida. Algunos rabinos consideran que mientras haya muerte encefálica pero el corazón siga latiendo, esa persona está aún viva y se estaría produciendo su muerte al extraer sus órganos. En cambio otros señalan que la muerte encefálica define la muerte del individuo, ya que a esta le seguirá inevitablemente el paro cardio-respiratorio ${ }^{10}$. Es importante mencionar esto, ya que si la definición de muerte encefálica fuese sólo por estímulos de corteza, no caería dentro de la definición de muerte, ya que no llevaría al inevitable cese de la respiración. La "Sociedad Halájica de donación de Órganos" (HODS), cuya misión es aumentar la donación de órganos de parte de los judíos a la población general señala que cuando el paciente deja de respirar, y aunque su corazón siga latiendo, éste será considerado muerto. El criterio de esta última opinión que es adoptada por la mayoría de las comunidades judías tanto ortodoxas como conservadoras, lleva a permitir la donación de órganos dentro del judaísmo actualmente.

En síntesis, existe un debate rabínico referente a la muerte encefálica y a la extracción de órganos. Una premisa de la opción judía es el valor supremo de la vida y es por esto que salvar una vida se antepone al respeto de ciertas prohibiciones contenidas en el Antiguo Testamento. Sin embargo, es complicado y equívoco intentar definir una línea única por cuanto existen diversas interpretaciones teológicas y recomendaciones. Si bien una minoría en el judaísmo se opone a la donación de órganos de cadáver, la posición judía mayoritaria no difiere significativamente del pensamiento occidental contemporáneo y está a favor de la donación.

La Torá dice "Hazte de un maestro, adquiere para ti un amigo y juzga a toda persona para bien"11. Es por eso que la postura que se tendrá frente a la donación de órganos, dependerá de la línea del Rabino que guíe a la persona en su conducción religiosa, debiendo en caso necesario, ser asesorado por un rabino experto en el tema.

Es importante destacar el conocimiento de otras culturas y religiones con objeto de lograr un adecuado "procuramiento" de órganos, respetando todas las creencias. Esto debe ser parte del proceso educativo que se debería entregar a los profesionales y a la comunidad en general. Es imperativo que las familias discutan su posición con respecto a ser donante o no y que los cercanos de un donante presunto conozcan y respeten su voluntad al momento de decidir sobre la donación de órganos, a pesar de la modificación legal reciente, que establece en nuestro país la donación presunta.

\section{Referencias}

1. Organización Nacional de Trasplantes [Internet]. España: Organización Nacional de Trasplantes. [Acceso 6 de mayo de 2011]. Disponible en: http://www.ont.es/ infesp/Memorias/Memoria_Donantes_2010.pdf

2. Corporación del Trasplante [Internet]. Santiago: Corporación Nacional del Trasplante [actualizada el 4 de marzo de 2011, acceso 4 de marzo de 2011]. Disponible en: http:// www.trasplante.cl/estadisticas/2010/resumen/02.php

3. Corporación del Trasplante [Internet]. Santiago: Corporación Nacional del Trasplante [actualizada el 4 de marzo de 2011, acceso 4 de marzo de 2011]. Disponible en: http://www.trasplante.cl

4. The United Synagogue of Conservative Judaism [Internet]. New York: United Synagogue of Conservative Judaism. [Acceso 9 de marzo de 2011]. Resolution of Organ and Tissue Donation (1997). Disponible en: http://www.uscj.org/Organ_and_Tissue_Don6706.html

5. Rosner F. Contemporary Byomedical Ethical Issues and Jewish Law. Jersey City: KTAV Publishing House, Inc.; 2007. p. 138.

6. Halachic Organ Donor Society [Internet]. Halachic Organ Donor Society. [Acceso 3 de diciembre de 2010]. Disponible en: http://www.hods.org/English/h-issues/ issues.asp

7. Ley $\mathrm{N}^{\circ} 20413$-modifica la Ley $\mathrm{N}^{\circ} 19.451$, con el fin de determinar quiénes pueden ser considerados donantes de órganos y la forma en que pueden manifestar su voluntad.

8. Abraham A. The comprehensive guide to Medical Halachah. Jerusalem: Feldheim Publishers; 1996. p. 178-92.

9. Flores JC, Pérez M, Thambo S, Valdivieso A. Muerte encefálica bioética y trasplante de órganos. Rev Med Chile 2004; 132 (1): 109-18.

10. The Dr. Falk Schlesinger Institute for Medical-Halachical Research. Jewish Medical Ethics. Vol 1. Jerusalem, Halpering M, Fink D, Glick S. Jerusalem: 2004. p. 367 427.

11. Tratado de Pirkei Avot. Capítulo 1. Mishná 6. 